\title{
Calcium Signal Profiles in Vascular Endothelium from Cdh5-GCaMP8 and Cx40-GCaMP2 Mice
}

\author{
Yen Lin Chen ${ }^{a}$ Thomas M. Baker ${ }^{a}$ Frank Lee $^{b}$ Bo Shui ${ }^{b}$ Jane C. Lee ${ }^{b}$ \\ Petr Tvrdik $^{c}$ Michael I. Kotlikoff ${ }^{b}$ Swapnil K. Sonkusare ${ }^{a, d}$ \\ aRobert M. Berne Cardiovascular Research Center, University of Virginia, Charlottesville, VA, USA; \\ bepartment of Biomedical Sciences, College of Veterinary Medicine, Cornell University, Ithaca, NY, USA; \\ 'Departments of Neurosurgery and Neuroscience and Bioengineering, University of Virginia, Charlottesville, VA, USA; \\ ${ }^{\mathrm{d} D e p a r t m e n t}$ of Molecular Physiology and Biological Physics, University of Virginia, Charlottesville, VA, USA
}

\section{Keywords}

Endothelium · Calcium · GCaMP · Arteries · Veins · Capillaries

\begin{abstract}
Introduction: Studies in Cx40-GCaMP2 mice, which express calcium biosensor GCaMP2 in the endothelium under connexin 40 promoter, have identified the unique properties of endothelial calcium signals. However, Cx40-GCaMP2 mouse is associated with a narrow dynamic range and lack of signal in the venous endothelium. Recent studies have proposed many GCaMPs (GCaMP5/6/7/8) with improved properties although their performance in endothelium-specific calcium studies is not known. Methods: We characterized a newly developed mouse line that constitutively expresses GCaMP8 in the endothelium under the VE-cadherin (Cdh5-GCaMP8) promoter. Calcium signals through endothelial IP3 receptors and TRP vanilloid 4 (TRPV4) ion channels were recorded in mesenteric arteries (MAs) and veins from Cdh5-GCaMP8 and Cx40-GCaMP2 mice. Results: Cdh5-GCaMP8 mice showed lower baseline fluorescence intensity, higher dynamic range, and higher amplitudes of individual calcium signals than Cx40-GCaMP2 mice. Importantly, Cdh5-GCaMP8 mice enabled the first recordings of discrete calcium signals in the intact venous endothelium and revealed striking differences
\end{abstract}

in IP3 receptor and TRPV4 channel calcium signals between MAs and mesenteric veins. Conclusion: Our findings suggest that Cdh5-GCaMP8 mice represent significant improvements in dynamic range, sensitivity for low-intensity signals, and the ability to record calcium signals in venous endothelium.

(c) 2021 S. Karger AG, Basel

\section{Introduction}

An increase in cytosolic $\mathrm{Ca}^{2+}$ is an essential regulator of cellular functions in mammalian cells. The majority of physiological $\mathrm{Ca}^{2+}$ activity in mammalian cells occurs as fast, spatially restricted signals [1]. Genetically encoded $\mathrm{Ca}^{2+}$ indicators (GECIs) have proved immensely helpful in real-time recordings of individual $\mathrm{Ca}^{2+}$ signals [2-6]. Among the many GECIs developed so far, GCaMPs remain the preferred variants for detecting $\mathrm{Ca}^{2+}$ signals in mammalian cells under physiological conditions [2-6]. GCaMPs are composed of a circularly permutated GFP (cpGFP) flanked by the M13 fragment of myosin lightchain kinase (M13), a target sequence of calmodulin $(\mathrm{CaM})$, on the N-terminus and by $\mathrm{CaM}$ on the C-terminus [7]. The binding of $\mathrm{Ca}^{2+}$ to CaM triggers a conforma-

$\begin{aligned} & \text { karger@karger.com } \\ & \text { www.karger.com/jvr }\end{aligned}$
Karger ${ }^{\prime /}$

Swapnil K. Sonkusare

School of Medicine, University of Virginia

409 Lane Road, PO Box 801394

Charlottesville, VA 22908 (USA)

sks2n@virginia.edu 
tional change in cpEGFP, causing an increase in fluorescence intensity [7]. GCaMPs also offer advantages over $\mathrm{Ca}^{2+}$-indicator dyes, including decreased cytotoxicity, cell type-specific expression, higher resistance to photobleaching [8], and a vastly increased experimental duration, as GCaMPs, unlike $\mathrm{Ca}^{2+}$-indicator dyes, cannot be pumped out of the cells.

Depending on the cell type under consideration, a variety of $\mathrm{Ca}^{2+}$-permeable ion channels underlie discrete $\mathrm{Ca}^{2+}$ signals. Therefore, the unique spatial and kinetic properties of $\mathrm{Ca}^{2+}$ signals provide crucial insights into the ion channel behavior. GCaMPs have enabled the studies of spatial and kinetic properties of individual $\mathrm{Ca}^{2+}$ signals in mammalian tissues [3-5,9]. Over the past decade, the use of mice constitutively expressing GCaMP2 in endothelial cells (ECs) under connexin 40 promoter (Cx40GCaMP2 mice) has resulted in the discoveries of different $\mathrm{Ca}^{2+}$ signals that control arterial function $[2,3]$. These signals include inositol 1,4,5-trisphosphate receptor (IP3R)-mediated $\mathrm{Ca}^{2+}$ release from the endoplasmic reticulum $\left(\mathrm{Ca}^{2+}\right.$ pulsars $)[2,3,10]$, the influx of extracellular $\mathrm{Ca}^{2+}$ through transient receptor potential (TRP) channels on EC membranes ( $\mathrm{Ca}^{2+}$ sparklets) $[2,9,11]$, and IP3Rmediated propagating $\mathrm{Ca}^{2+}$ waves $[4,5]$. Despite the advancements made using Cx40-GCaMP2 mice, lower dynamic range and brightness, and a high baseline fluorescence limit their utility. Moreover, Cx40-GCaMP2 mice cannot be used to image endothelial $\mathrm{Ca}^{2+}$ signals in veins.

Since the development of what is now termed GCaMP1 [7], several alterations to the structure have been undertaken to improve brightness, dynamic range, temperature stability, dimerization prevention, baseline fluorescence, and overall functionality of GCaMPs [5, 12-16]. GCaMP2 has been the most commonly used $\mathrm{Ca}^{2+}$ biosensor in arterial endothelium $[2,3,9,10,17,18]$. Although other studies have used GCaMP5 and GCaMP7 to record endothelial $\mathrm{Ca}^{2+}$ signals in zebrafish models $[19,20]$, these biosensors have not been used for studies on the intact endothelium. GCaMP8 is the latest in the series of GCaMP biosensors and offers advantages over other GCaMPs with improved dynamic range $\left(F_{\max } / F_{\min }=38\right)[12]$ and kinetic properties. However, the performance of GCaMP8 in studies of $\mathrm{Ca}^{2+}$ in the intact endothelium is not known. Moreover, the properties of individual $\mathrm{Ca}^{2+}$ signals in the intact endothelium from mice constitutively expressing GCaMP8 in ECs remain unknown.

In this study, we characterized a newly developed mouse line that constitutively expresses GCaMP8 in the endothelium under control of the VE-cadherin (Cdh5GCaMP8) promotor and compared the signature proper- ties of individual $\mathrm{Ca}^{2+}$ signals in the intact endothelium from Cx40-GCaMP2 and Cdh5-GCaMP8 mice. PdgfbGCaMP5 mice, which express a commonly used GECI, GCaMP5, in ECs, were used as an additional control group for comparing the properties of endothelial $\mathrm{Ca}^{2+}$ signals. Cdh5-GCaMP8 mice showed lower baseline fluorescence intensity and a higher dynamic range than $\mathrm{Cx} 40$ GCaMP2 mice. The average amplitudes of IP3R $\mathrm{Ca}^{2+}$ signals were higher with Cdh5-GCaMP8 mice, improving their detectability. Cdh5-GCaMP8 mice also showed a higher amplitude for unitary $\mathrm{Ca}^{2+}$ influx events through TRP vanilloid 4 (TRPV4) channels, termed TRPV4 $\mathrm{Ca}^{2+}$ sparklets. Importantly, Cdh5-GCaMP8 mice enabled the first recordings of distinct $\mathrm{Ca}^{2+}$ signals in the intact venous endothelium and revealed striking differences in IP3R and TRPV4 $\mathrm{Ca}^{2+}$ signals between veins and arteries. In contrast with Cx40-GCaMP2 mice, Cdh5-GCaMP8 mice also allowed the visualization of capillaries.

\section{Materials and Methods}

\section{Animal Models}

The University of Virginia Animal Care and Use Committee and Cornell Institutional Animal Care and Use Committee approved all protocols. All procedures adhered to the standards published in the Guide for the Care and Use of Laboratory Animals. Male Cx40-GCaMP2 [4, 5], Cdh5-GCaMP8 mice, and PdgfbGCaMP5 mice were used in the present study.

\section{Generation of Cdh5-GCaMP8 Mice}

Cdh5-GCaMP8 mice were generated by the Cornell University Resource for Optogenetic Mouse Signaling (CHROMus) as previously described [21]. The GCaMP8 expression cassette was inserted at the translational initiation site downstream of the Cdh5 promoter in bacterial artificial chromosome (BAC) clone RP23-453P1 (BACPAC Resources, Emeryville, CA, USA) by homologous recombination in Escherichia coli strain SW105 [4]. The linearized DNA was microinjected into B6SJLF/J embryos using standard pronuclear injection techniques. Founder mice were identified by PCR using primers specific for both $5^{\prime}$ and $3^{\prime}$ junction sequences and backcrossed to C57BL6 mice.

Generation of Pdgfb-GCaMP5 Mice

PC::G5-tdT reporter mouse [22] that expresses the GCaMP5 $\mathrm{Ca}^{2+}$ indicator and IRES-tdTomato in a Cre-dependent fashion was crossed with tamoxifen-inducible form of endothelial Pdgfb Cre (iCreERT2) [23]. The expression of GCaMP5 and tdTomato was induced by 5 i.p. injections of tamoxifen $(2 \mathrm{mg} / 20 \mathrm{mg}$ body weight, 1 injection per day), followed by a 2 -week washout period.

\section{Genotyping}

Samples of ear tissue were treated with the HotSHOT lysis buffer $(25 \mathrm{~mm} \mathrm{NaOH}$ and $0.2 \mathrm{mM}$ EDTA) and neutralized with an equal volume $40 \mathrm{~mm}$ Tris- $\mathrm{HCl}$ to extract genomic DNA. PCRs 
were prepared using 1 unit Bioline MangoTaq DNA Polymerase (London, England), 5x Colored Reaction Buffer for MangoTaq DNA Polymerase, $1.5 \mathrm{mM} \mathrm{MgCl}_{2}, 200 \mu \mathrm{M}$ of each dNTP, $1 \mu \mathrm{M} 5^{\prime}$ and $3^{\prime}$ primers, and $100-250 \mathrm{ng}$ of the extracted DNA. The reaction mixture was then run in a Bio-Rad T100 Thermal Cycler (Hercules, CA, USA). PCR products were loaded into a $1 \%$ agarose gel containing $0.2 \mu \mathrm{g} / \mu \mathrm{L}$ ethidium bromide in TAE Buffer $(40 \mathrm{~mm}$ Tris Base, $20 \mathrm{~mm}$ Acetic Acid, and $1 \mathrm{~mm}$ EDTA). The gels were run in a Genesee Scientific Midi Horizontal Gel Box (San Diego, CA, USA) at $90 \mathrm{~V}$ using a Bio-Rad PowerPac HC High-Current Power Supply. Gels were exposed to $302 \mathrm{~nm}$ UV light for visualization. A New England BioLabs 100 bp DNA Ladder (Ipswich, MA, USA) was used for comparison. For Cx40-GCaMP2, samples were heated to $94^{\circ} \mathrm{C}$ for $1 \mathrm{~min}$, cycled 30 times through $94^{\circ} \mathrm{C}$ for $20 \mathrm{~s}, 60^{\circ} \mathrm{C}$ for $30 \mathrm{~s}$, and $72^{\circ} \mathrm{C}$ for $2 \mathrm{~min}$, and then held at $72^{\circ} \mathrm{C}$ for $10 \mathrm{~min}$. For Cdh5-GCaMP8, samples were heated to $94^{\circ} \mathrm{C}$ for $3 \mathrm{~min}$, cycled 30 times through $94^{\circ} \mathrm{C}$ for $30 \mathrm{~s}, 57^{\circ} \mathrm{C}$ for $30 \mathrm{~s}$, and $72^{\circ} \mathrm{C}$ for $1 \mathrm{~min}$, and then held at $72^{\circ} \mathrm{C}$ for $5 \mathrm{~min}$. The genotyping primers used were as follows: Cx40-GCaMP2, 5' CAGAGCATGATGGGACCTTC, 3' GGTTTCCGGGCCCTCACATT and Cdh5-GCaMP8, 5' AAGGGCGAGGAGCTGTTCA， $3^{\prime}$ CGATCTGCTCTTCAGTCAGTTGGT. All primers were sourced from Eurofins Genomics (Louisville, KY, USA).

\section{$\mathrm{Ca}^{2+}$ Imaging}

Third-order mesenteric arteries (MAs; $~ 100 \mu \mathrm{m}$ ) were isolated in ice-cold Hepes-buffered physiological salt solution (Hepes-PSS; $10 \mathrm{~mm}$ Hepes, $134 \mathrm{mM} \mathrm{NaCl}, 6 \mathrm{mM} \mathrm{KCl}, 1 \mathrm{mM} \mathrm{MgCl}_{2}$ hexahydrate, $2 \mathrm{mM} \mathrm{CaCl}_{2}$ dihydrate, and $7 \mathrm{~mm}$ dextrose, $\mathrm{pH}$ adjusted to 7.4 with $\mathrm{NaOH}) . \mathrm{Ca}^{2+}$ imaging studies were performed using methods described previously $[2,24,25]$. Third-order MAs or mesenteric veins (MVs) were cut open and pinned down en face on SYLGARD blocks. Images were acquired at 15 frames per second using Andor Revolution WD (with Borealis) spinning-disk confocal imaging system (Oxford Instruments, Abingdon, UK) comprising an upright Nikon microscope with a $\times 60$ water dipping objective (numerical aperture 1.0) and an electron-multiplying charge-coupled device camera (iXon 888, Oxford Instruments, Abingdon, UK). MAs and MVs were superfused with bicarbonate-buffered PSS (199 $\mathrm{mm} \mathrm{NaCl}, 4.7 \mathrm{mM} \mathrm{KCl}, 1.2 \mathrm{mM} \mathrm{KH}_{2} \mathrm{PO}_{4}, 1.2 \mathrm{mM} \mathrm{MgCl}_{2}$ hexahydrate, $2.5 \mathrm{mM} \mathrm{CaCl}_{2}$ dihydrate, $7 \mathrm{mM}$ dextrose, and $24 \mathrm{mM} \mathrm{NaH}$ $\mathrm{CO}_{3}$ ). To maintain a $\mathrm{pH}$ of 7.4 , PSS was bubbled with $20 \% \mathrm{O}_{2}$ and $5 \% \mathrm{CO}_{2}$. GCaMPs were excited at $488 \mathrm{~nm}$ with a solid-state laser, and emitted fluorescence was captured using a 525/36 nm bandpass filter. All the experiments were performed at $37^{\circ} \mathrm{C}$.

The arteries and veins were treated with cyclopiazonic acid (CPA; SERCA inhibitor, $20 \mu \mathrm{M}$ ) or xestospongin C (IP3R inhibitor, $8 \mu \mathrm{M}$ ) for $10 \mathrm{~min}$ in some experiments. In a subset of experiments, arteries were treated with GSK1016790A (GSK101, TRPV4 channel activator, $10 \mathrm{nM}$ ) or GSK2193874 (GSK219, TRPV4 channel inhibitor, $100 \mathrm{nM}$ ) for $10 \mathrm{~min}$. Minimum fluorescence intensity $\left(F_{\min }\right)$ was obtained by using $\mathrm{Ca}^{2+}$-free PSS and 5 mM EGTA $\left(\mathrm{Ca}^{2+}\right.$ chelator). Maximum fluorescence intensity $\left(F_{\max }\right)$ was obtained in the presence of ionomycin $(10 \mu \mathrm{M})$ and $20 \mathrm{mM} \mathrm{Ca}^{2+}$ to calculate $F_{\max }$.

For visualizing the capillaries, a $z$-stack was performed on the intestinal wall encompassing a total distance of $100 \mu \mathrm{m}$ along the $z$-axis, and at a slice size of $0.5 \mu \mathrm{m}$. A 3-dimensional volume rendering was performed using Imaris version 9.3 (Bitplane AG, Zurich, Switzerland).

Endothelial Calcium Activity with GCaMP2 and GCaMP8
Analysis of IP3R $\mathrm{Ca}^{2+}$ Pulsars and TRPV4 $\mathrm{Ca}^{2+}$ Sparklets

A custom-designed program (by Dr. Adrian Bonev, University of Vermont) was used to analyze $\mathrm{Ca}^{2+}$ images. IP3R signals were automatically detected using a threshold of $1.25 \mathrm{~F} / \mathrm{F}_{0}$ and a scanbox of $7 \times 7$ pixels. To account for a changing baseline (movement of the artery or change of focus), an average image was created and $F_{\min }$ was obtained every 20 images. For each event site, frequency, average amplitude, average rise time (time of rise from half-maximal amplitude to the peak), average duration (maximum width at half-maximal amplitude), and average decay halflife (time of decay from peak to half-maximal amplitude) were determined. The numbers were averaged for each artery. For the analysis of endothelial TRPV4 sparklets, regions of interest of 1.7 $\mu \mathrm{m}^{2}(5 \times 5$ pixels) were placed at the peak event amplitude to obtain fractional fluorescent traces $\left(F / F_{0}\right)$. A Gaussian filter with a $4-\mathrm{Hz}$ cutoff corner frequency was applied to the representative $F / F_{0}$ traces.

Two different parameters were used to indicate endothelial TRPV4 sparklet activity: (1) sparklet sites per cell and (2) sparklet activity per site. TRPV4 $\mathrm{Ca}^{2+}$ sparklet activity per site was evaluated as described previously $[9,26]$. Area under the curve for all the events at a site was determined using trapezoidal numerical integration $\left(\left[F-F_{0}\right] / F_{0}\right.$ over time, in seconds). The average number of active TRPV4 channels, as defined by $\mathrm{NP}_{\mathrm{O}}$ (where $N$ is the number of channels at a site and $P_{\mathrm{O}}$ is the open-state probability of the channel), was calculated by

$$
\mathrm{NP}_{\mathrm{O}}=\left(\mathrm{T}_{\text {level } 1}+2 \mathrm{~T}_{\text {level } 2}+3 \mathrm{~T}_{\text {level 3 }}+4 \mathrm{~T}_{\text {level } 4}\right) / \mathrm{T}_{\text {total }}
$$

where $T$ is the dwell time at each quantal level detected at TRPV4 sparklet sites and $T_{\text {total }}$ is the duration of the recording. $\mathrm{NP}_{\mathrm{O}}$ was determined using Single-Channel Search module of Clampfit and quantal amplitudes derived from all-points histograms [11].

\section{All-Points Histogram Construction}

Histograms were constructed from the $F / F_{0}$ traces. An ImageJ plug in that utilizes a filter gain of 0.8 , and an acquisition noise variance of estimate of 0.05 (Christopher Philip Mauer, Northwestern University, Chicago, IL, USA) was used to apply Kalman filter to the images. Steady peaks containing at least 5 data points and a stable baseline containing at least 5 steady points were used as the inclusion criteria. Clampfit10.3 was used to construct an allpoints histogram from sparklet traces using the following multiple Guassian function:

$$
f\left(F / F_{0}\right)=\sum_{i=1}^{N} \frac{a i}{\sqrt{2 \pi \sigma i}} \exp \left[\frac{-\left(\frac{F}{F 0}-\mu i\right)^{2}}{2 \sigma i^{2}}\right],
$$

where $\mu$ represents the mean value, a represents the area, $\sigma^{2}$ is the variance of the Guassian distribution, and $F / F_{0}$ represents the fractional fluorescence.

\section{Statistics}

Data were analyzed using independent or paired 2-tailed $t$ test and 1-way ANOVA. Tukey correction was performed for post hoc testing if data were significant. A $p$ value of $<0.05$ was used to de- 


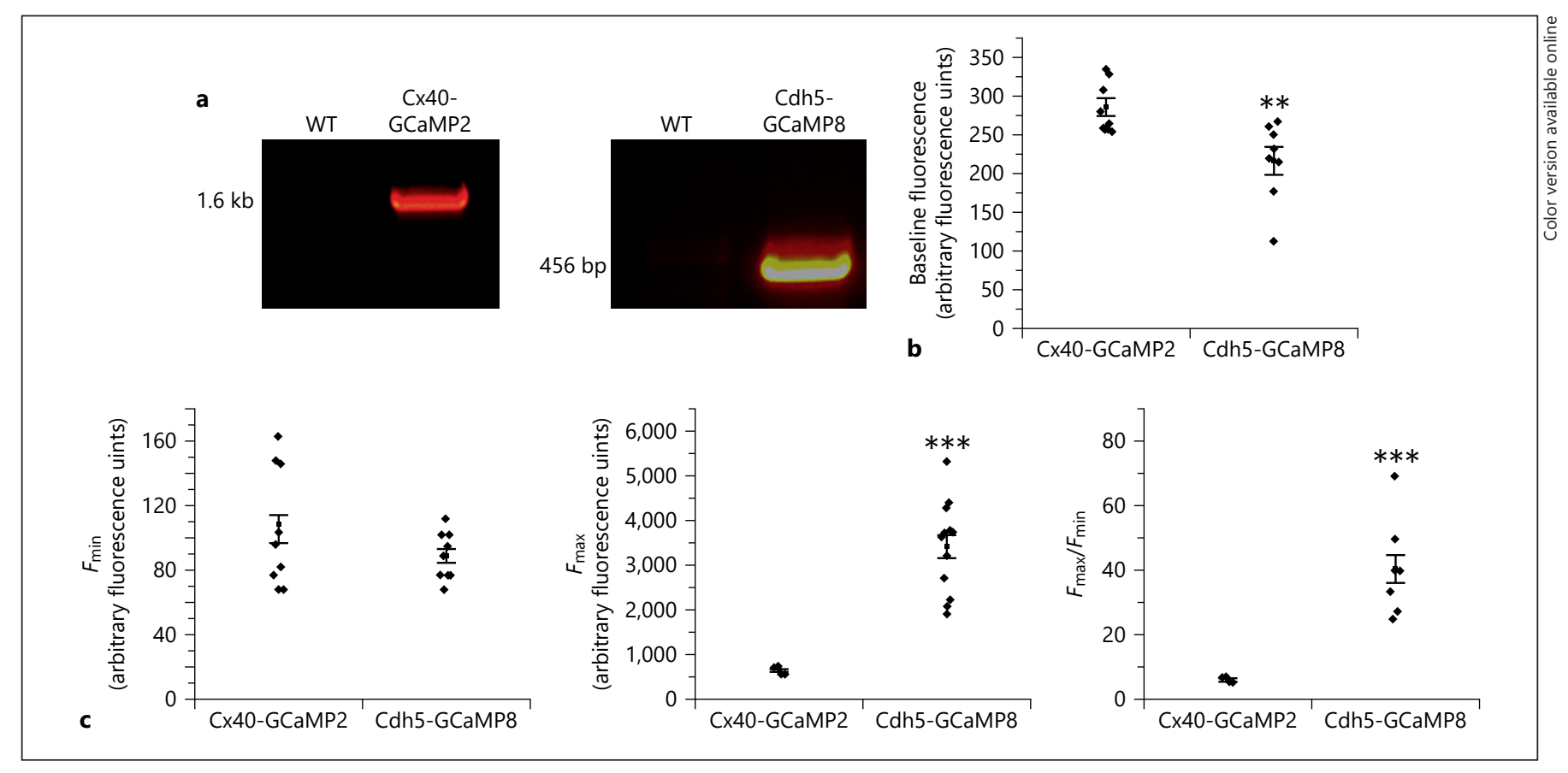

Fig. 1. a Left: Cx40-GCaMP2 PCR results on a $1 \%$ agarose gel indicating a wild-type sample with no reaction product and Cx40-GCaMP2 sample showing a positive reaction product at $1.6 \mathrm{kbp}$; right: Cdh5-GCaMP8 PCR results on a $1 \%$ agarose gel showing a wild-type sample with no reaction product and a Cdh5-GCaMP8 sample with a positive reaction product at $456 \mathrm{bp}$. b Baseline fluorescence values in MAs from Cx40-GCaMP2 and Cdh5GCaMP8 mice $\left(n=8,{ }^{* *} p<0.01, t\right.$ test). c Comparisons of $F_{\min }$ (left, $\left.n=8\right), F_{\max }$ (middle, $\left.n=9\right)$, and dynamic range $\left(F_{\max } / F_{\min }\right.$, right, $\left.n=7\right)$ between the arteries from Cx40-GCaMP2 mice and Cdh5-GCaMP8 mice; ${ }^{* *} p<$ $0.01,{ }^{* * *} p<0.001, t$ test. MAs, mesenteric arteries; $F_{\min }$, minimum fluorescence; $F_{\max }$, maximum fluorescence.

termine statistical significance. Normality was determined using Shapiro-Wilk tests. Parametric statistics were performed as all data were normally distributed. OriginPro 7.5 (Northampton, MA, USA) was used for all statistical analysis. CorelDraw Graphics Suite X7 (Ottawa, ON, Canada) was used to prepare all graphical data. One artery or vein was considered as $n=1$. The individual data points for each site in the artery were averaged to obtain the data value for 1 artery.

\section{Results}

Endothelium from Cdh5-GCaMP8 Mice Shows Lower Baseline Fluorescence and Higher Dynamic Range Than the Endothelium from Cx40-GCaMP2 Mice

We used high-speed imaging to record $\mathrm{Ca}^{2+}$ signals in MAs from the newly developed Cdh5-GCaMP8 mouse and compared the properties of $\mathrm{Ca}^{2+}$ signals with those in the extensively used Cx40-GCaMP2 mouse. Mouse genotypes were confirmed via PCR (shown in Fig. 1a). The baseline whole-cell fluorescence intensity in ECs was calculated using EC outlines as regions of interest. The base- line fluorescence intensity was significantly lower in ECs from Cdh5-GCaMP8 mice when compared to the Cx40GCaMP2 mice (shown in Fig. 1b). $F_{\text {min }}$ was obtained in the presence of $\mathrm{Ca}^{2+}$-free PSS containing $0 \mathrm{mM} \mathrm{Ca}^{2+}$ and $5 \mathrm{mM}$ EGTA ( $\mathrm{Ca}^{2+}$ chelator). $F_{\text {min }}$ was not different between the arteries from Cdh5-GCaMP8 mice and Cx40GCaMP2 mice (shown in Fig. 1c, left). $F_{\max }$ was calculated in the presence of ionomycin $(10 \mu \mathrm{M})$ and $20 \mathrm{mM}$ $\mathrm{Ca}^{2+}$. The increase in fluorescence induced by ionomycin was homogenous, indicating that GCaMP2 and GCaMP8 were expressed evenly in the endothelium. $F_{\max }$ was $\sim 6$ times higher in the arteries from Cdh5-GCaMP8 mice than the arteries from Cx40-GCaMP2 mice (shown in Fig. 1c, middle). $F_{\max } / F_{\text {min }}$ ratio was also $\sim 6$-fold higher in Cdh5-GCaMP8 mice when compared to Cx40GCaMP2 mice (shown in Fig. 1c, right). These results confirmed that the Cdh5-GCaMP8 mouse offers significant advantages with respect to lower baseline fluorescence and a higher dynamic range in the intact endothelium. 
Fig. 2. Recordings of IP3R-mediated $\mathrm{Ca}^{2+}$ signals $\left(\mathrm{Ca}^{2+}\right.$ pulsars) in en face MAs from Cx40-GCaMP2, Cdh5-GCaMP8, and Pdgfb-GCaMP5 mice. The experiments were performed in the presence of TRPV4 channel inhibitor GSK2193874 (GSK219, $100 \mathrm{nM}$ ). a Representative traces of $\mathrm{Ca}^{2+}$ signals in Cx40-GCaMP2 mice in the absence or presence of IP3R inhibitor xestospongin $\mathrm{C}(8 \mu \mathrm{M}$, top 2 traces) and in the absence or presence of SERCA inhibitor CPA $(20 \mu \mathrm{M}$, bottom 2 traces) b Representative $F / F_{0}$ traces of $\mathrm{Ca}^{2+}$ pulsars in MAs from Cdh5-GCaMP8 mice in the absence or presence of IP3R inhibitor xestospongin C. c Representative $F / F_{0}$ traces of $\mathrm{Ca}^{2+}$ pulsars in MAs from Cdh5-GCaMP8 mice in the absence or presence of CPA. d Representative $F / F_{0}$ traces of $\mathrm{Ca}^{2+}$ pulsars in MAs from Cdh5-GCaMP8 mice in the absence or presence of muscarinic receptor agonist CCh $(10 \mu \mathrm{M})$. e Representative images for GCaMP5 and tdTomato fluorescence in the endothelium from MAs of PdgfbGCaMP5 mice (left) and representative $\mathrm{Ca}^{2+}$ pulsar activity (right). IP3R, inositol 1,4,5-trisphosphate receptor; MAs, mesenteric arteries; TRPV4, transient receptor potential vanilloid 4; CPA, cyclopiazonic acid.

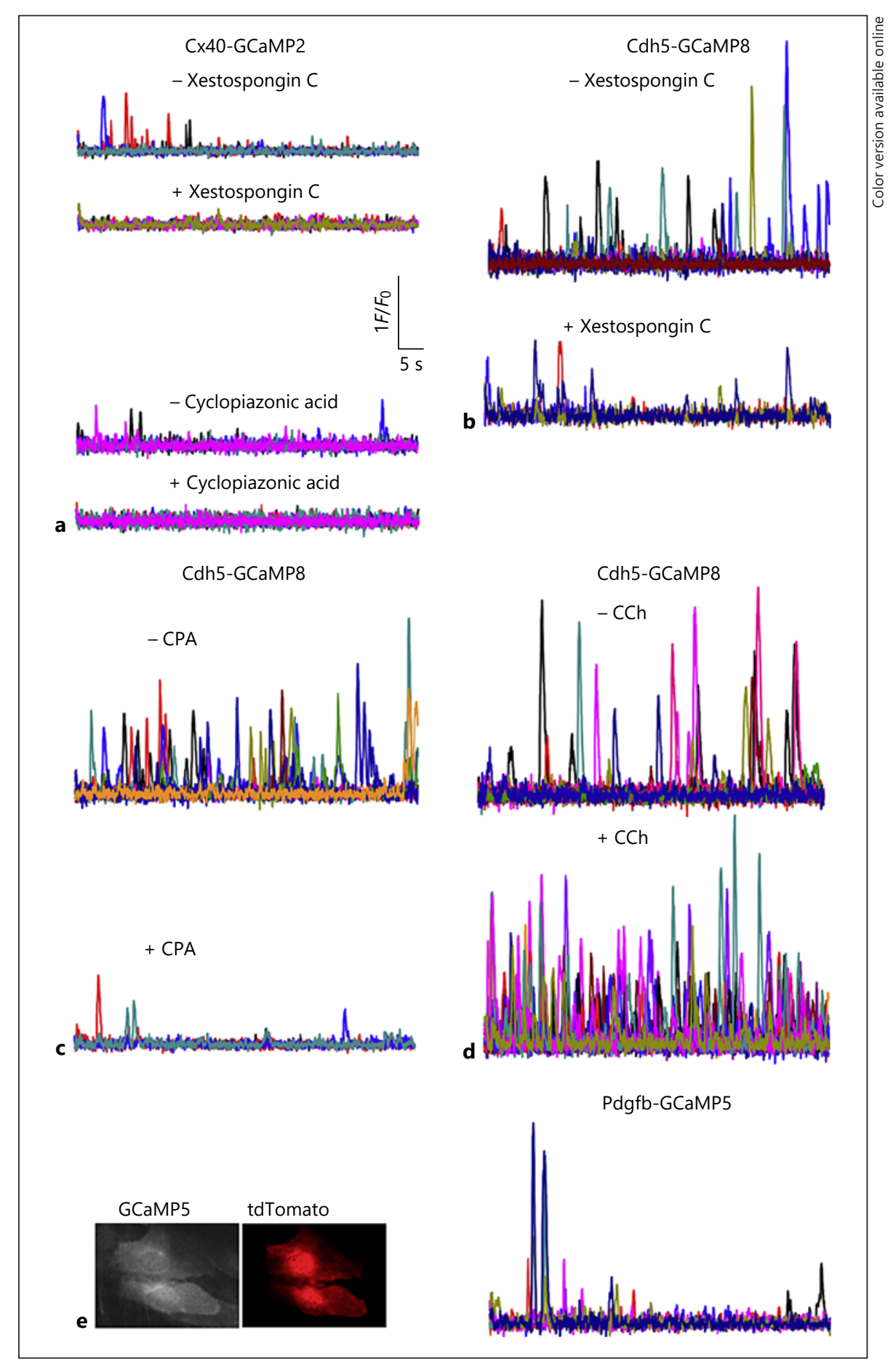

Cdh5-GCaMP8 Mice Show Higher Amplitudes,

Frequency, and Number of Sites for IP3R $\mathrm{Ca}^{2+}$ Signals

Than Cx40-GCaMP2 Mice

Recordings of IP3R-mediated $\mathrm{Ca}^{2+}$ signals in small MAs were performed in the presence of TRPV4 channel inhibitor GSK2193874 (GSK219; $100 \mathrm{nM}$ ) to eliminate
$\mathrm{Ca}^{2+}$ influx signals through TRPV4 channels. The remaining $\mathrm{Ca}^{2+}$ signals were inhibited by xestospongin $\mathrm{C}(8$ $\mu \mathrm{M}$; an IP3R antagonist, shown in Fig. 2a, b) or CPA (20 $\mu \mathrm{M}$; a sarcoendoplasmic reticulum $\mathrm{Ca}^{2+}$-ATPase inhibitor, shown in Fig. 2a, c), indicating that most of the $\mathrm{Ca}^{2+}$ signal activity in the presence of TRPV4 channel inhibitor 
represented IP3R-mediated $\mathrm{Ca}^{2+}$ release from the ER in MAs. Consistent with previous studies in Cx40-GCaMP2 mice, muscarinic receptor activator, carbachol (CCh, 10 $\mu \mathrm{M})$, increased the activity of IP3R $\mathrm{Ca}^{2+}$ signals in MAs from Cdh5-GCaMP8 mice (shown in Fig. 2d). IP3R-mediated $\mathrm{Ca}^{2+}$ signals in Cx40-GCaMP2 mice have previously been labelled $\mathrm{Ca}^{2+}$ pulsars [3]. $\mathrm{A} \mathrm{Ca}^{2+}$ pulsar was defined as an increase to at least 1.25 in $F / F_{0}$ (observed fluorescence divided by minimum fluorescence over 10 images) from the baseline of $1 F / F_{0}$. The averaged peak amplitude of $\mathrm{Ca}^{2+}$ pulsars was higher $\left(F / F_{0}=2.10\right)$ in Cdh5-GCaMP8 mice when compared to that in Cx40GCaMP2 mice $\left(F / F_{0}=1.61\right.$; shown in Table 1 ; see online suppl. Videos 1, 2; for all online suppl. material, see www. karger.com/doi/10.1159/000514210). MAs from Cdh5GCaMP8 mice also showed a higher number of $\mathrm{Ca}^{2+}$ pulsar sites per cell when compared to $\mathrm{Cx} 40-\mathrm{GCaMP} 2$ mice (shown in Table 1). Moreover, the frequency of $\mathrm{Ca}^{2+}$ pulsars per site was higher ( 0.086 per second) in the arteries from Cdh5-GCaMP8 mice than the arteries from $\mathrm{Cx} 40$ GCaMP2 mice (0.034 per second).
GCaMP5 is another GECI commonly used for recording $\mathrm{Ca}^{2+}$ signals in mammalian cells although the evidence on $\mathrm{Ca}^{2+}$ signals using GCaMP5 in the intact endothelium is scarce. We used a Pdgfb-GCaMP5 mouse that expresses $\mathrm{Ca}^{2+}$ biosensor GCaMP5 and tdTomato in ECs under the tamoxifen-inducible Pdgfb promoter [22, 23]. Endothelial expression of GCaMP5 correlated with the expression of reporter tdTomato (shown in Fig. 2e). The frequency and amplitude of IP3R $\mathrm{Ca}^{2+}$ signals in MAs from Pdgfb-GCaMP5 mice were higher than Cx40GCaMP2 mice but lower than Cdh5-GCaMP8 mice (shown in Fig. 2e; Table 1).

\section{Rise Time, Duration, and Half-Life of Endothelial}

IP3R $\mathrm{Ca}^{2+}$ Signals Are Not Different among Cx40-

GCaMP2, Cdh5-GCaMP8, and Pdgfb-GCaMP5 Mice

The rise time (time of rise from half-maximal amplitude to the peak), duration (maximum width at half-maximal amplitude), and decay half-life (time of decay from peak to half-maximal amplitude) of IP3 $\mathrm{R} \mathrm{Ca}^{2+}$ signals were calculated to determine whether the kinetic proper-

Table 1. Quantitation of the properties of IP3R $\mathrm{Ca}^{2+}$ signals in small MAs from Cx40-GCaMP2, Cdh5-GCaMP8, and Pdgfb-GCaMP5 mice

\begin{tabular}{lccc}
\hline IP3R signals & Cx40-GCaMP2 & Cdh5-GCaMP8 & Pdgfb-GCaMP5 \\
\hline Frequency, Hz & $0.034 \pm 0.003$ & $0.086 \pm 0.002^{* * *}$ & $0.049 \pm 0.006^{* *},+\dagger \dagger$ \\
+ CCh & $0.061 \pm 0.005$ & $0.151 \pm 0.006^{* * *}$ & $0.095 \pm 0.005^{* *},+\dagger \dagger$ \\
\hline Sites per cell & $0.32 \pm 0.04$ & $1.85 \pm 0.38^{* * *}$ & $1.0 \pm 0.22^{* * *},+\dagger \dagger$ \\
+ CCh & $0.67 \pm 0.05$ & $3.2 \pm 0.30^{* * *}$ & $2.1 \pm 0.14^{* * *,+\dagger \dagger}$ \\
\hline Amplitude, $F / F_{0}$ & $1.42 \pm 0.008$ & $2.10 \pm 0.01^{* * *}$ & $1.61 \pm 0.049^{* *},+\dagger$ \\
\hline Rise time, ms & $247 \pm 21$ & $287 \pm 19$ & $317 \pm 20$ \\
\hline Duration, ms & $464 \pm 16$ & $510 \pm 23$ & $518 \pm 16$ \\
\hline Decay, $t_{1 / 2}, m s$ & $277 \pm 15$ & $297 \pm 12$ & $337 \pm 25$ \\
\hline Maximum amplitude, $F / F_{0}$ & 2.59 & 7.59 & 4.37 \\
\hline
\end{tabular}

Data are represented as mean \pm SEM. A 1-way ANOVA with post hoc Tukey test was used to test statistical significance among groups ( $n=5$ arteries). MAs, mesenteric arteries; IP3R, inositol 1,4,5-trisphosphate receptor. ${ }^{* *} p<0.01 .{ }^{* * *} p<0.001$ versus Cx40-GCaMP2. ${ }^{\dagger \dagger} p<0.01 .{ }^{\dagger \dagger \dagger} p<0.001$ versus Cdh5-GCaMP8.

Fig. 3. Recordings of elementary $\mathrm{Ca}^{2+}$ influx signals through endothelial TRPV4 channels (TRPV4 sparklets) in en face MAs from Cx40-GCaMP2, Cdh5-GCaMP8, and Pdgfb-GCaMP5 mice. Left panel: representative $F / F_{0}$ traces of TRPV4 sparklet sites in MAs from Cx40-GCaMP2 (top), Cdh5-GCaMP8 (middle), and PdgfbGCaMP5 (bottom) mice. The sparklets were recorded in the presence of CPA $(20 \mu \mathrm{M})$ and TRPV4 channel activator GSK1016790A (GSK101, $10 \mathrm{nM}$ ) in the absence or presence of TRPV4 channel inhibitor GSK219 (100 nM). Dotted red lines represent the quantal levels (single-channel amplitudes) determined from all-points histograms. Right panel: all-points amplitude histograms in MAs from Cx40-GCaMP2 (top), Cdh5-GCaMP8 (middle), and PdgfbGCaMP5 (bottom) mice. The histograms were fit with a multiGaussian curve. The peaks on the multi-Gaussian curve were quantal. TRPV4, transient receptor potential vanilloid 4; MAs, mesenteric arteries; CPA, cyclopiazonic acid.

(For figure see next page.) 
Cx40-GCaMP2

CPA + GSK101, $10 \mathrm{nM}$

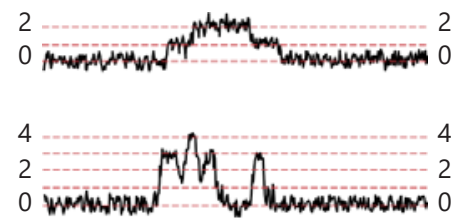

+ GSK219, 100 nM

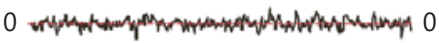

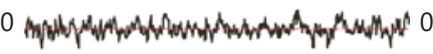

Cdh5-GCaMP8

CPA + GSK101, $10 \mathrm{nM}$

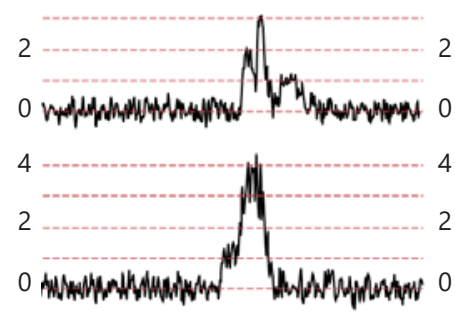

+ GSK219, $100 \mathrm{nM}$

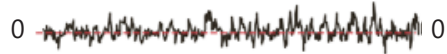

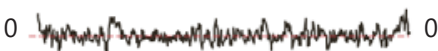

Pdgfb-GCaMP5 CPA + GSK101, $10 \mathrm{nM}$

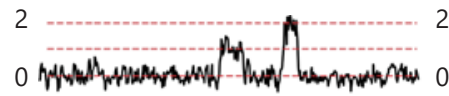

2 ond 2

+ GSK219, $100 \mathrm{nM}$

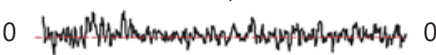

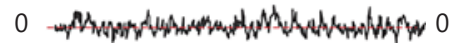

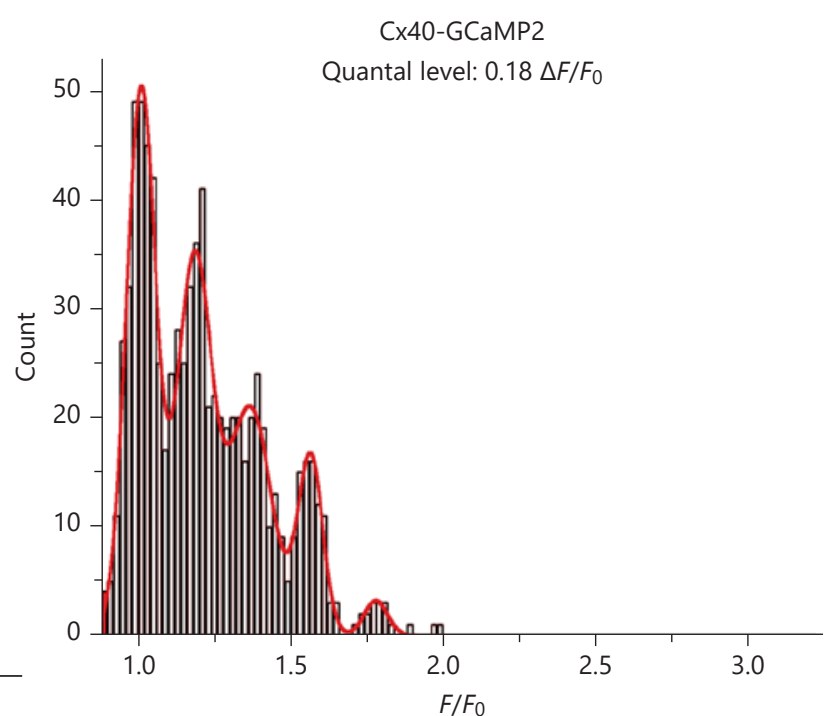

Cdh5-GCaMP8

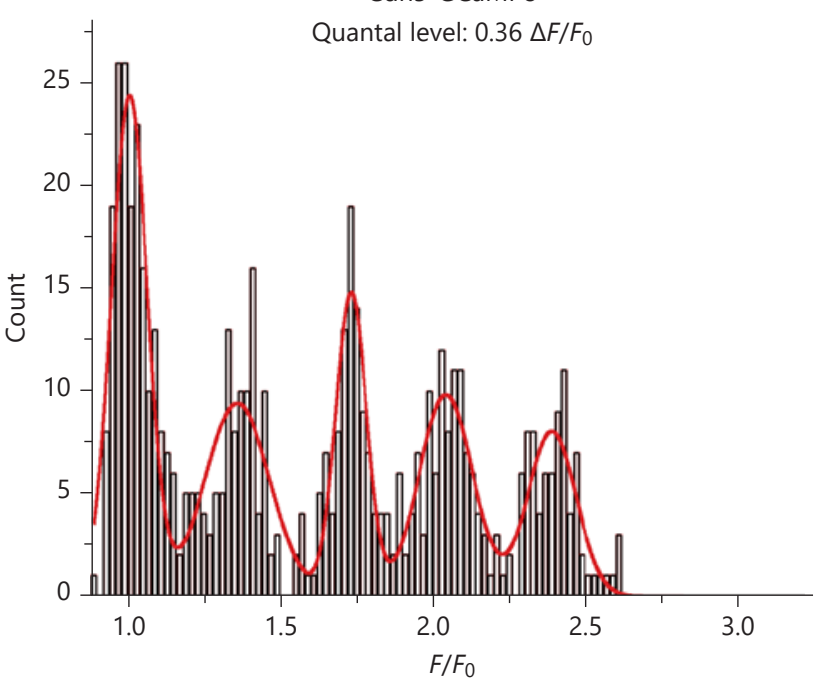

Pdgfb-GCaMP5

Quantal level: $0.30 \Delta F / F_{0}$

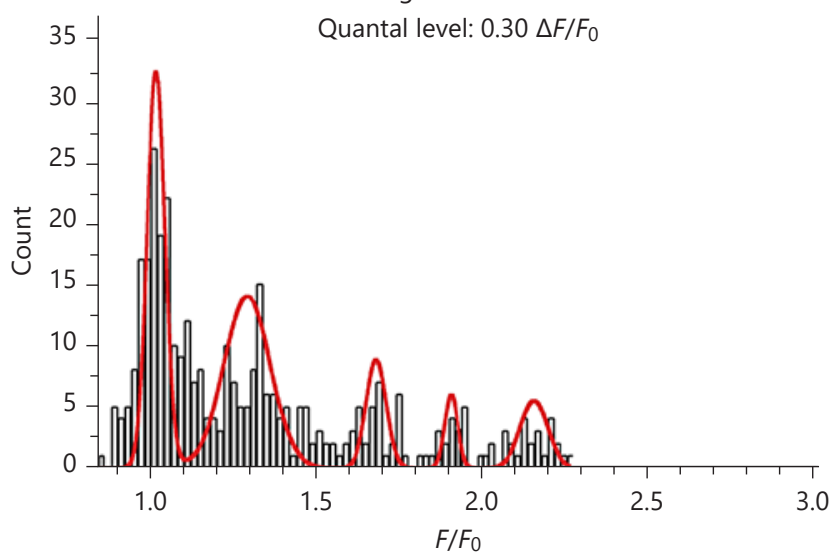




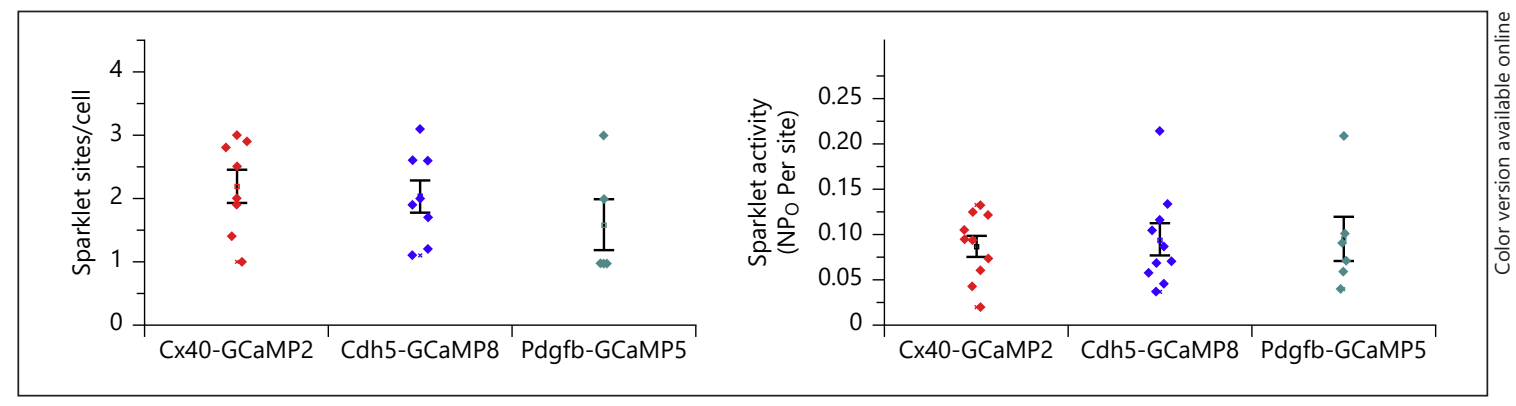

Fig. 4. Quantification of endothelial TRPV4 sparklet activity in MAs from Cx40-GCaMP2, Cdh5-GCaMP8, and Pdgfb-GCaMP5 mice. Experiments were performed in the presence of CPA (20 $\mu \mathrm{M})$ and GSK101 (10 nM). Left: averaged TRPV4 sparklet sites per endothelial cell in MAs from Cx40-GCaMP2, Cdh5-GCaMP8, and PdgfbGCaMP5 mice $(n=5)$. Right: averaged TRPV4 sparklet activity per site $\left(\mathrm{NP}_{\mathrm{O}}\right.$ per site, where $N$ is the number of channels and $P_{\mathrm{O}}$ is the open state probability) in Cx40-GCaMP2, Cdh5-GCaMP8, and Pdgfb-GCaMP5 mice $(n=5)$. TRPV4, transient receptor potential vanilloid 4; MAs, mesenteric arteries; CPA, cyclopiazonic acid.

ties of IP3 $\mathrm{R} \mathrm{Ca}^{2+}$ signals are different in Cx40-GCaMP2, Cdh5-GCaMP8, and Pdgfb-GCaMP5 mice. The rise time, duration, and decay half-life of IP3 $\mathrm{R} \mathrm{Ca}^{2+}$ signals were not different among Cx40-GCaMP2, Cdh5-GCaMP8, and Pdgfb-GCaMP5 mice (shown in Table 1). These results suggested that although the amplitude and frequency of IP3 $\mathrm{R} \mathrm{Ca}^{2+}$ signals vary among the 3 mice, their kinetic properties do not change (shown in Table 1).

\section{Endothelial TRPV4 Sparklet Amplitude Is Higher} in Cdh5-GCaMP8 Mice, but Sparklet Activity and

Number of Sparklets Sites per Cell Are Not Different

Elementary $\mathrm{Ca}^{2+}$ influx signals through endothelial TRPV4 channels (TRPV4 sparklets [9]) were recorded in the presence of CPA $(20 \mu \mathrm{M})$ to eliminate interference from intracellular $\mathrm{Ca}^{2+}$ release signals. Experiments were performed in the presence of TRPV4 channel activator GSK1016790A (GSK101, 10 nM). GSK2193874 (GSK219, TRPV4 inhibitor, $100 \mathrm{nM}$ )-sensitive TRPV4 sparklet activity was seen in MAs from Cx40-GCaMP2, Cdh5GCaMP8, and Pdgfb-GCaMP5 mice (shown in Fig. 3). All-points amplitude histograms obtained from the $F / F_{0}$ traces were fit with a multi-Gaussian curve, and the peaks of the curve were quantal, a characteristic single-channel behavior $[9,11,25,26]$. The quantal level (single-channel amplitude) was higher in the Cdh5-GCaMP8 mice (0.36 $\left.\Delta F / F_{0}\right)$ when compared to the Cx40-GCaMP2 mice $(0.18$ $\left.\Delta F / F_{0}\right)$, consistent with higher intensity of GCaMP8 versus GCaMP2 (shown in Fig. 3). The quantal amplitude of TRPV4 sparklets in MAs from Pdgfb-GCaMP5 (0.30 $\left.\Delta F / F_{0}\right)$ was higher than that in Cx40-GCaMP2 mice but lower than the quantal amplitude observed in Cdh5GCaMP8 mice (shown in Fig. 3). The number of TRPV4 sparklet sites per endothelial cell, however, was not different among Cdh5-GCaMP8, Cx40-GCaMP2, and PdgfbGCaMP5 mice (shown in Fig. 4). TRPV4 sparklet activity at each site was calculated as $\mathrm{NP}_{\mathrm{O}}$ per site, where $N$ is the number of channels and $P_{\mathrm{O}}$ is the open-state probability of the channel $[25,26]$. TRPV4 sparklet activity per site was not different between the 3 mice (shown in Fig. 4), supporting the idea that although Cdh5-GCaMP8 and Pdgfb-GCaMP5 mice offer the benefit of higher amplitudes, the sensitivity of detection of TRPV4 sparklets is unaltered among the 3 mice.

\section{Lower IP3R $\mathrm{Ca}^{2+}$ Signal and Higher TRPV4 Sparklet}

Activity in Venous Endothelium Compared to Arterial

Endothelium

The properties of individual $\mathrm{Ca}^{2+}$ signals in venous endothelium are relatively unknown. Therefore, we recorded IP3 $\mathrm{R} \mathrm{Ca}^{2+}$ release signals and TRPV4 sparklets in the intact endothelium from third-order MVs. Previous studies suggest that Cdh5 is expressed in the venous endothelium [27]; however, Cx40 is absent [28]. Accordingly, Cx40-GCaMP2 mice showed no baseline fluorescence or transient $\mathrm{Ca}^{2+}$ signals in MVs (shown in Fig. 5a). In the MVs from Cdh5-GCaMP8 mice, however, robust $\mathrm{Ca}^{2+}$ activity was observed under baseline conditions (shown in online suppl. Video 3). The activity of IP3R $\mathrm{Ca}^{2+}$ signals was recorded in the presence of TRPV4 channel inhibitor GSK219. Similar to MAs, the majority of the baseline $\mathrm{Ca}^{2+}$ signals were inhibited by CPA (shown in Fig. 5b), indicating that these signals were $\mathrm{Ca}^{2+}$ release events from intracellular stores. For IP3 $\mathrm{R} \mathrm{Ca}^{2+}$ signals, the number of sites per cell and frequency per site were lower in MVs than in MAs, indicating a lower activity of 
Fig. 5. a Representative greyscale images showing endothelium from third-order MVs of Cx40-GCaMP2 (left) and Cdh5GCaMP8 (right) mice. b Representative $F / F_{0}$ traces for IP3R-mediated $\mathrm{Ca}^{2+}$ signals in endothelium from MVs of Cdh5GCaMP8 mice under basal conditions (top) and in the presence of CPA (bottom). c Representative $F / F_{0}$ traces for endothelial TRPV4 sparklets in MVs from Cdh5GCaMP8 mice in the presence of CPA (20 $\mu \mathrm{M})$ and TRPV4 channel activator GSK1016790A (GSK101, 10 nM, top) and after the addition of TRPV4 channel inhibitor GSK219 (100 nM, bottom). d Three-dimensional volumetric rendering of images of intestinal wall of Cx40-GCaMP2 (left) and Cdh5-GCaMP8 (right) mice. Images were acquired along the $z$-axis for a distance of $100 \mu \mathrm{m}$ from top of the intestinal wall (slice size $=0.5 \mu \mathrm{m})$. MVs, mesenteric veins; IP3R, inositol 1,4,5-trisphosphate receptor; CPA, cyclopiazonic acid; TRPV4, transient receptor potential vanilloid 4 .

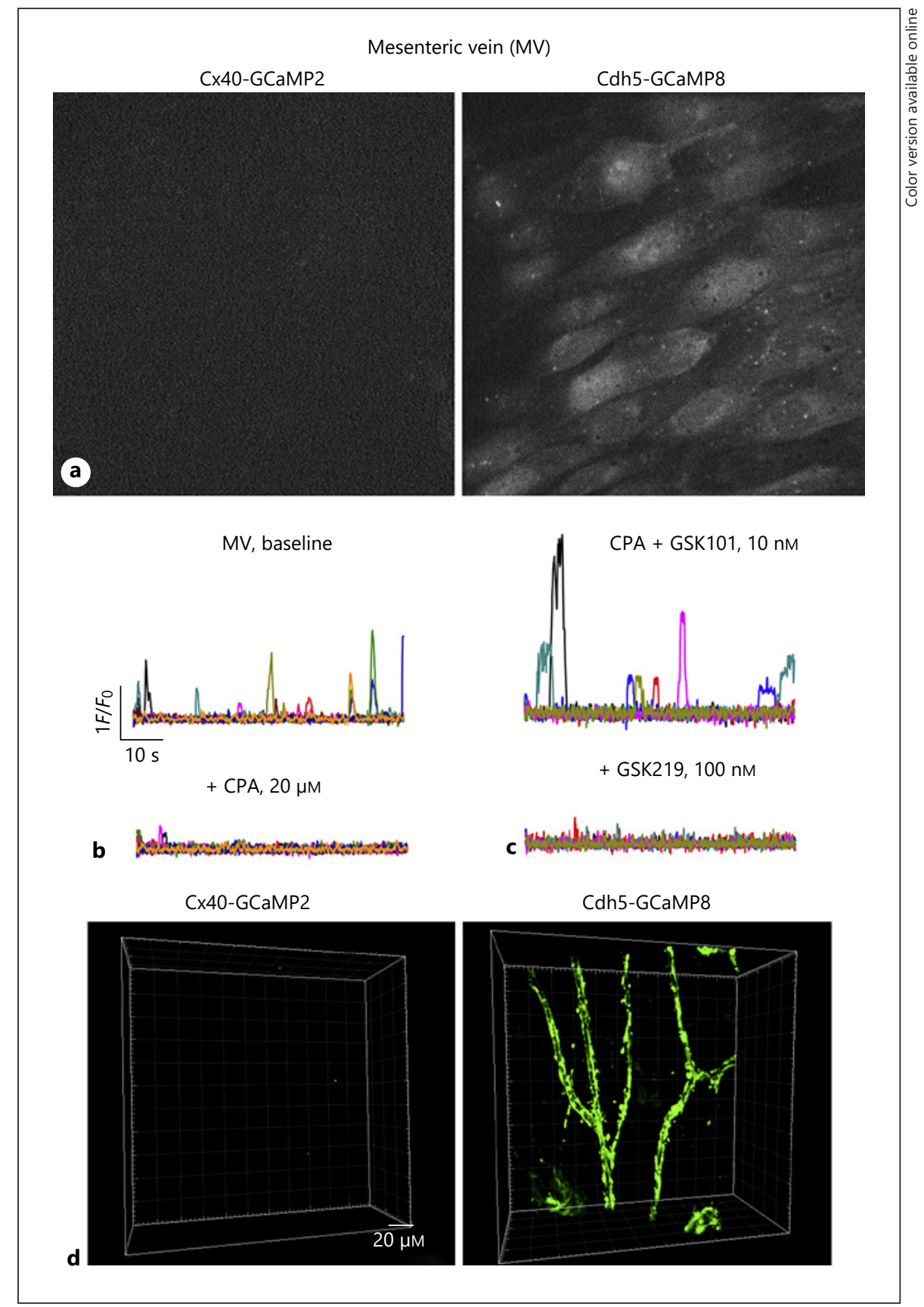

IP3Rs in MVs (shown in Table 2). The average peak amplitude of IP3R Ca ${ }^{2+}$ signals was also lower in MVs than in MAs (shown in Table 2). The signature kinetic properties of IP3 $\mathrm{R} \mathrm{Ca}^{2+}$ signals (rise time, duration, and decay half-life), however, were not different between MAs and MVs (shown in Table 2). In the presence of CPA, endothelium from MVs showed TRPV4 sparklet activity that was increased by TRPV4 channel activator GSK101 and inhibited by TRPV4 channel inhibitor GSK219 (shown in Fig. 5c). Importantly, TRPV4 sparklet activity per endothelial cell and sparklet activity per site were significantly higher in MVs when compared to MAs (shown in Table 3). In MAs, we previously reported that endothelial TRPV4 channels exist as four-channel metastructures. In MVs, however, a maximum of 8 open TRPV4 channels were observed at a site (shown in Table 3). These results 
Table 2. Quantitation of the properties of IP3R-mediated baseline $\mathrm{Ca}^{2+}$ signals in small mesenteric arteries and small MVs from Cdh5-GCaMP8 mice

\begin{tabular}{lcc}
\hline $\begin{array}{l}\text { IP3R signals, baseline, } \\
\text { Cdh5-GCaMP8 }\end{array}$ & Artery & Vein \\
\hline Frequency, Hz & & \\
Sites per cell & $0.086 \pm 0.002$ & $0.024 \pm 0.004^{* * *}$ \\
Amplitude, $F / F_{0}$ & $1.85 \pm 0.38$ & $0.40 \pm 0.09^{* * *}$ \\
Rise time, ms & $2.10 \pm 0.01$ & $1.65 \pm 0.07^{* * *}$ \\
Duration, ms & $287 \pm 12$ & $305 \pm 26$ \\
Decay, $t_{1 / 2}, \mathrm{~ms}$ & $510 \pm 3$ & $545 \pm 31$ \\
\hline
\end{tabular}

Data are represented as mean \pm SEM. Student's $t$ test was used to compare signals from arteries and veins. A $p$ value of $<0.05$ was used to declare statistical significance $(n=5)$. MVs, mesenteric veins; IP3R, inositol 1,4,5-trisphosphate receptor. ${ }^{* * *} p<0.001$.

supported the idea that IP3R activity is lower and TRPV4 channel activity is higher in MVs when compared to MAs.

\section{Visualization of Capillaries in Cdh5-GCaMP8 Mice}

Using a scan along the $z$-axis on the intestinal walls, capillaries were identified as microvessels with an internal diameter of $<5 \mu \mathrm{m}$. A bright GCaMP8 signal was observed in the capillaries from Cdh5-GCaMP8 mice (shown in Fig. 5d). The GCaMP2 signal was, however, absent in the capillaries from Cx40-GCaMP2 mice (shown in Fig. 5d).

\section{Discussion/Conclusion}

The use of GECI to record $\mathrm{Ca}^{2+}$ signals in the intact endothelium has mostly been limited to Cx40-GCaMP2 mice. Recent studies have revealed several new GCaMPs, although the properties of $\mathrm{Ca}^{2+}$ signals with newer GCaMPs have not been tested in the intact endothelium. Moreover, the $\mathrm{Ca}^{2+}$ signal profiles in the intact venous endothelium are entirely unknown. In this manuscript, we present the kinetic profiles of $\mathrm{Ca}^{2+}$ signals in the intact endothelium from a newly developed Cdh5-GCaMP8 mouse. The arteries from Cdh5-GCaMP8 mice showed lower baseline fluorescence, higher dynamic range, and higher amplitudes of individual $\mathrm{Ca}^{2+}$ signals, while the kinetic properties of the signals remained unchanged. Importantly, Cdh5-GCaMP8 mice enabled visualization of $\mathrm{Ca}^{2+}$ signals in venous endothelium and revealed major differences in IP3R and TRPV4 $\mathrm{Ca}^{2+}$ signals between ar- terial and venous endothelium. While many GCaMPs with improved properties over GCaMP2 have been discovered, Cx40-GCaMP2 and Cdh5-GCaMP8 are the only mice that constitutively express GECIs in endothelium and allow the visualization of $\mathrm{Ca}^{2+}$ signals in the intact endothelium without interference from $\mathrm{Ca}^{2+}$ activity in surrounding smooth muscle cells.

Previous studies identified 2 main sources of increases in intracellular $\mathrm{Ca}^{2+}$ in the endothelium from mesenteric arteries: IP3R-mediated $\mathrm{Ca}^{2+}$ release from the endoplasmic reticulum and $\mathrm{Ca}^{2+}$ influx through TRPV4 ion channels on endothelial cell membrane $[2,3,9,10]$. The recordings of IP3 $\mathrm{R} \mathrm{Ca}^{2+}$ signals in this study were performed in the presence of TRPV4 channel inhibitor GSK219, whereas the recordings of TRPV4 channel $\mathrm{Ca}^{2+}$ influx signals (TRPV4 sparklets) were performed in the presence of CPA to eliminate intracellular $\mathrm{Ca}^{2+}$ release signals. In $\mathrm{Cx} 40-\mathrm{GCaMP} 2$ mice, IP3R $\mathrm{Ca}^{2+}$ signals have been termed $\mathrm{Ca}^{2+}$ pulsars [3]. The frequency per site and number of pulsar sites per cell were higher in MAs from Cdh5-GCaMP8 mice when compared to MAs from Cx40-GCaMP2 mice. In this regard, it is important to note that signal amplitude was higher and baseline fluorescence was lower in MAs from Cdh5-GCaMP8 mice. We postulate that the increase in the number of IP3R events in Cdh5-GCaMP8 mice was due to higher intensity of the biosensor. It is conceivable that the higher fluorescence intensity in Cdh5-GCaMP8 mice (compared to Cx40-GCaMP2 mice) allowed the detection of the lowintensity events that would fall below the detection threshold in Cx40-GCaMP2 mice, thereby increasing the number of event sites and the frequency per site. GCaMP8 is known to show a lower baseline brightness than GCaMP2 [12], which is the major contributor to the increase in signal range. Cdh5 is also expressed in distal cells [29], whereas Cx40 is principally arterial [30]. It is not known whether $\mathrm{Cx} 40$ drives stronger or weaker expression than Cdh5 in arterial cells.

In contrast to IP3 $\mathrm{R} \mathrm{Ca}^{2+}$ signals, the number of sites for TRPV4 sparklets and activity per site was not different between Cx40-GCaMP2 and Cdh5-GCaMP8 mice, despite a clear increase in quantal amplitude of TRPV4 sparklets with Cdh5-GCaMP8 mice. The quantal amplitude of TRPV4 sparklets was $\sim 2$-fold higher in the arteries from Cdh5-GCaMP8 mice when compared to Cx40GCaMP2 mice. These findings suggested that the intensity of lowest-level TRPV4 sparklets was above the threshold of detection of GCaMP2, and therefore, increase in intensity did not offer additional benefit in terms of detecting more TRPV4 sparklet sites or events. As re- 
Table 3. Comparison of the properties of endothelial TRPV4 sparklets in small MAs and MVs from Cdh5GCaMP8 mice

\begin{tabular}{lcc}
\hline TRPV4 sparklets, $10 \mathrm{nM}$ GSK101, and Cdh5-GCaMP8 & Artery & Vein \\
\hline Activity per site $\left(\mathrm{NP}_{\mathrm{O}}\right)$ & $0.087 \pm 0.011$ & $0.254 \pm 0.060^{* * *}$ \\
Sites per cell & $2.10 \pm 0.01$ & $2.5 \pm 0.04^{* * *}$ \\
Maximum number of channels per site & 4 & 8
\end{tabular}

The experiments were performed in the presence of CPA $(20 \mu \mathrm{M})$ and TRPV4 channel activator GSK101 (10 $\mathrm{nM})$. Data are represented as mean \pm SEM. Student's $t$ test was used to compare the activity per site and sites per cell from small MAs and MVs $(n=5)$. TRPV4, transient receptor potential vanilloid 4; MAs, mesenteric arteries; MVs, mesenteric veins; CPA, cyclopiazonic acid. ${ }^{* * *} p<0.001$.

ported previously using Cx40-GCaMP2 mice [9], a 4 TRPV4 channel metastructure was also observed in the intact endothelium from Cdh5-GCaMP8 mice (Fig. 3).

$\mathrm{Ca}^{2+}$ signals in the intact arterial endothelium have been reported by numerous studies [2, 3, 31-35]. As a result, the signature properties of endothelial $\mathrm{Ca}^{2+}$ signals in the intact arterial endothelium are well established. However, individual $\mathrm{Ca}^{2+}$ signals and their signature properties remain unknown in the intact venous endothelium $[36,37]$. GECIs offer many advantages over $\mathrm{Ca}^{2+}$ indicators (e.g., fluo-4) including cell type-specific expression, more stable signal, significantly longer experiments (no efflux via membrane ATPases), and less photobleaching or phototoxicity. Our results confirm that Cx40-GCaMP2 mice cannot be used for recording $\mathrm{Ca}^{2+}$ activity in the venous endothelium due to the lack of $\mathrm{Cx} 40$ expression in venous endothelium. The use of Cdh5GCaMP8 mice allowed the recordings of individual $\mathrm{Ca}^{2+}$ signals in the intact venous endothelium and analysis of their signature properties. A detailed $\mathrm{Ca}^{2+}$ image analysis revealed 2 important differences in the activity of IP3R and TRPV4 $\mathrm{Ca}^{2+}$ signals between the intact endothelium from MAs and MVs: (1) the activity of IP3 $\mathrm{R} \mathrm{Ca}^{2+}$ signals is lower in veins than in arteries and (2) the activity of TRPV4 $\mathrm{Ca}^{2+}$ sparklets is higher in veins when compared to arteries. The mechanisms for the different activities of IP3R and TRPV4 $\mathrm{Ca}^{2+}$ signals between arteries and veins are not known and will require further investigation. Potential mechanisms include the following: (1) different expression levels of TRPV4 channels and IP3Rs in the arterial and venous endothelium; (2) distinct regulatory mechanisms for TRPV4 channels or IP3Rs in the arterial and venous endothelium; and (3) distinct IP3R isoforms in the arterial and venous endothelium.

In venous endothelium, the maximum number of TRPV4 channels per site was $\sim 8$, suggesting a different
TRPV4 cluster composition in veins when compared to arteries. These differences may indicate a more prominent role for TRPV4 channels than for IP3Rs as a pathway for increasing cytosolic $\mathrm{Ca}^{2+}$ in the venous endothelium. The differences may also indicate distinct functional roles of TRPV4 channels and IP3Rs in the venous endothelium. The physiological roles of IP3 $\mathrm{R} \mathrm{Ca}^{2+}$ signals and TRPV4 sparklets remain unknown in the venous endothelium. While only IP3R and TRPV4 $\mathrm{Ca}^{2+}$ signals were recorded in the intact venous endothelium in this study, other $\mathrm{Ca}^{2+}$ influx or release pathways may also play important functional roles. In this regard, TRPA1 and TRPV3 channels have been shown to be important $\mathrm{Ca}^{2+}$ influx pathways in arterial endothelium from other vascular beds $[34,38]$. Moreover, TRPP1 channels were recently proposed as an endothelial $\mathrm{Ca}^{2+}$ influx pathway that mediates flow-induced vasodilation [39]. Whether TRPA1/TRPV3/TRPP1 channels are functional in venous endothelium has not been investigated.

Recent studies indicate that TRPV4 channels can activate $\mathrm{Ca}^{2+}$ release through IP3Rs, thereby amplifying the TRPV4 channel-induced $\mathrm{Ca}^{2+}$ response and endothelium-dependent vasodilation. The findings that IP3R activity is lower in the venous endothelium may imply a less important role for TRPV4 channel-mediated vasodilation in veins compared to the arteries. Current evidence suggests that venous endothelium is more permeable than the arterial endothelium [40]. In this regard, endothelial TRPV4 channels have been shown to promote vascular permeability [41, 42]. Therefore, it is plausible that TRPV4 channels regulate venous endothelial permeability.

Our results provide detailed profiles of individual $\mathrm{Ca}^{2+}$ signals in the intact endothelium from newly developed Cdh5-GCaMP8 mouse. Our findings also suggest that studies in the intact endothelium from Cdh5-GCaMP8 
mice benefit from lower background fluorescence and higher dynamic range, and GCaMP8 expression in veins when compared to Cx40-GCaMP2 mice. Moreover, our studies reveal important differences in IP3R and TRPV4 $\mathrm{Ca}^{2+}$ signal activity between arteries and veins.

\section{Statement of Ethics}

The University of Virginia Animal Care and Use Committee and Cornell Institutional Animal Care and Use Committee approved all protocols. All the procedures adhered to the standards published in the Guide for the Care and Use of Laboratory Animals.

\section{Conflict of Interest Statement}

The authors have no conflicts of interest to declare.

\section{Funding Sources}

This work was supported by grants from the National Institutes of Health to SKS (HL146914 and HL142808).

\section{Author Contributions}

Y.L.C. and T.M.B. performed the experiments. Y.L.C., T.M.B. and S.K.S. analyzed the data. Y.L.C. and S.K.S. made the figures. F.L., B.S., J.C.L., P.T., and M.I.K. generated the mice. S.K.S. wrote the manuscript. All the authors read and approved the manuscript.

\section{References}

1 Ottolini M, Hong K, Sonkusare SK. Calcium signals that determine vascular resistance. Wiley Interdiscip Rev Syst Biol Med. 2019; 11(5):e1448.

2 Hong K, Cope EL, DeLalio LJ, Marziano C, Isakson BE, Sonkusare SK. TRPV4 (Transient Receptor Potential Vanilloid 4) channel-dependent negative feedback mechanism regulates $\mathrm{Gq}$ protein-coupled receptor-induced vasoconstriction. Arterioscler Thromb Vasc Biol. 2018;38(3):542-54.

3 Ledoux J, Taylor MS, Bonev AD, Hannah RM, Solodushko V, Shui B, et al. Functional architecture of inositol 1,4,5-trisphosphate signaling in restricted spaces of myoendothelial projections. Proc Natl Acad Sci U S A. 2008; 105(28):9627-32.

4 Tallini YN, Brekke JF, Shui B, Doran R, Hwang SM, Nakai J, et al. Propagated endothelial $\mathrm{Ca} 2+$ waves and arteriolar dilation in vivo: measurements in Cx40BAC GCaMP2 transgenic mice. Circ Res. 2007;101(12): $1300-9$.

5 Tallini YN, Ohkura M, Choi BR, Ji G, Imoto $\mathrm{K}$, Doran $\mathrm{R}$, et al. Imaging cellular signals in the heart in vivo: cardiac expression of the high-signal Ca2+ indicator GCaMP2. Proc Natl Acad Sci U S A. 2006;103(12):4753-8.

6 Kaestner L, Scholz A, Tian Q, Ruppenthal S, Tabellion W, Wiesen K, et al. Genetically encoded $\mathrm{Ca} 2+$ indicators in cardiac myocytes. Circ Res. 2014;114(10):1623-39.

7 Nakai J, Ohkura M, Imoto K. A high signalto-noise $\mathrm{Ca} 2+$ probe composed of a single green fluorescent protein. Nat Biotechnol. 2001;19(2):137-41.

8 Thomas D, Tovey SC, Collins TJ, Bootman MD, Berridge MJ, Lipp P. A comparison of fluorescent $\mathrm{Ca} 2+$ indicator properties and their use in measuring elementary and global Ca2+ signals. Cell Calcium. 2000;28(4):21323.

9 Sonkusare SK, Bonev AD, Ledoux J, Liedtke W, Kotlikoff MI, Heppner TJ, et al. Elemen- tary Ca2 + signals through endothelial TRPV4 channels regulate vascular function. Science. 2012;336(6081):597-601.

10 Nausch LW, Bonev AD, Heppner TJ, Tallini Y, Kotlikoff MI, Nelson MT. Sympathetic nerve stimulation induces local endothelial $\mathrm{Ca} 2+$ signals to oppose vasoconstriction of mouse mesenteric arteries. Am J Physiol Heart Circ Physiol. 2012;302(3):H594-602.

11 Marziano C, Hong K, Cope EL, Kotlikoff MI, Isakson BE, Sonkusare SK. Nitric oxide-dependent feedback loop regulates transient receptor potential vanilloid 4 (TRPV4) channel cooperativity and endothelial function in small pulmonary arteries. J Am Heart Assoc. 2017;6(12):e007157.

12 Ohkura M, Sasaki T, Sadakari J, Gengyo-Ando K, Kagawa-Nagamura Y, Kobayashi C, et al. Genetically encoded green fluorescent $\mathrm{Ca} 2+$ indicators with improved detectability for neuronal Ca2+ signals. PLoS One. 2012; 7(12):e51286

13 Akerboom J, Chen TW, Wardill TJ, Tian L, Marvin JS, Mutlu S, et al. Optimization of a GCaMP calcium indicator for neural activity imaging. J Neurosci. 2012;32(40):13819-40.

14 Chen TW, Wardill TJ, Sun Y, Pulver SR, Renninger SL, Baohan A, et al. Ultrasensitive fluorescent proteins for imaging neuronal activity. Nature. 2013;499(7458):295-300.

15 Dana H, Sun Y, Mohar B, Hulse BK, Kerlin AM, Hasseman JP, et al. High-performance calcium sensors for imaging activity in neuronal populations and microcompartments. Nat Methods. 2019;16(7):649-57.

16 Tian L, Hires SA, Mao T, Huber D, Chiappe $\mathrm{ME}$, Chalasani $\mathrm{SH}$, et al. Imaging neural activity in worms, flies and mice with improved GCaMP calcium indicators. Nat Methods. 2009;6(12):875-81.

17 Bagher P, Davis MJ, Segal SS. Visualizing calcium responses to acetylcholine convection along endothelium of arteriolar networks in Cx40BAC-GCaMP2 transgenic mice. Am J
Physiol Heart Circ Physiol. 2011;301(3): H794-802.

18 Bagher P, Davis MJ, Segal SS. Intravital macrozoom imaging and automated analysis of endothelial cell calcium signals coincident with arteriolar dilation in $\mathrm{Cx} 40(\mathrm{BAC})$ GCaMP2 transgenic mice. Microcirculation. 2011;18(4):331-8.

19 Liu C, Wu C, Yang Q, Gao J, Li L, Yang D, et al. Macrophages mediate the repair of brain vascular rupture through direct physical adhesion and mechanical traction. Immunity. 2016;44(5):1162-76.

20 Yokota Y, Nakajima H, Wakayama Y, Muto A, Kawakami K, Fukuhara S, et al. Endothelial Ca2+ oscillations reflect VEGFR signaling-regulated angiogenic capacity in vivo. Elife. 2015;4:e08817.

21 Shui B, Lee JC, Reining S, Lee FK, Kotlikoff MI. Optogenetic sensors and effectors: CHROMus-the cornell heart lung blood institute resource for optogenetic mouse signaling. Front Physiol. 2014;5:428.

22 Gee JM, Smith NA, Fernandez FR, Economo $\mathrm{MN}$, Brunert $\mathrm{D}$, Rothermel $\mathrm{M}$, et al. Imaging activity in neurons and glia with a Polr2abased and cre-dependent GCaMP5G-IREStdTomato reporter mouse. Neuron. 2014; 83(5):1058-72.

23 Claxton S, Kostourou V, Jadeja S, Chambon P, Hodivala-Dilke K, Fruttiger M. Efficient, inducible Cre-recombinase activation in vascular endothelium. Genesis. 2008;46(2):74-80.

24 Ottolini M, Daneva Z, Chen YL, Cope EL, Kasetti RB, Zode GS, et al. Mechanisms underlying selective coupling of endothelial $\mathrm{Ca} 2+$ signals with eNOS vs. IK/SK channels in systemic and pulmonary arteries. J Physiol. 2020 Sep; 598(17):3577-96.

25 Ottolini M, Hong K, Cope EL, Daneva Z, DeLalio LJ, Sokolowski JD, et al. Local peroxynitrite impairs endothelial TRPV4 channels and elevates blood pressure in obesity. Circulation. 2020 Apr 21;141(16):1318-33. 
26 Sonkusare SK, Dalsgaard T, Bonev AD, HillEubanks DC, Kotlikoff MI, Scott JD, et al. AKAP150-dependent cooperative TRPV4 channel gating is central to endothelium-dependent vasodilation and is disrupted in hypertension. Sci Signal. 2014;7(333):ra66.

27 Helker CS, Schuermann A, Karpanen T, Zeuschner D, Belting HG, Affolter M, et al. The zebrafish common cardinal veins develop by a novel mechanism: lumen ensheathment. Development. 2013;140(13):2776-86.

28 Buschmann I, Pries A, Styp-Rekowska B, Hillmeister P, Loufrani L, Henrion D, et al. Pulsatile shear and Gja5 modulate arterial identity and remodeling events during flow-driven arteriogenesis. Development. 2010;137(13): 2187-96.

29 Herwig MC, Müller KM, Müller AM. Endothelial VE-cadherin expression in human lungs. Pathol Res Pract. 2008;204(10):725-30.

30 Ivanova E, Kovacs-Oller T, Sagdullaev BT. Domain-specific distribution of gap junctions defines cellular coupling to establish a vascular relay in the retina. J Comp Neurol. 2019; 527(16):2675-93.

31 Bagher P, Beleznai T, Kansui Y, Mitchell R, Garland CJ, Dora KA. Low intravascular pressure activates endothelial cell TRPV4 channels, local $\mathrm{Ca} 2+$ events, and IKCa channels, reducing arteriolar tone. Proc Natl Acad Sci U S A. 2012;109(44):18174-9.
32 Francis M, Waldrup JR, Qian X, Solodushko V, Meriwether J, Taylor MS. Functional tuning of intrinsic endothelial $\mathrm{Ca} 2+$ dynamics in swine coronary arteries. Circ Res. 2016; 118(7):1078-90.

33 Naik JS, Osmond JM, Walker BR, Kanagy NL. Hydrogen sulfide-induced vasodilation mediated by endothelial TRPV4 channels. Am J Physiol Heart Circ Physiol. 2016;311(6): H1437-H44.

34 Sullivan MN, Gonzales AL, Pires PW, Bruhl A, Leo MD, Li W, et al. Localized TRPA1 channel $\mathrm{Ca} 2+$ signals stimulated by reactive oxygen species promote cerebral artery dilation. Sci Signal. 2015;8(358):ra2.

35 Tran CH, Taylor MS, Plane F, Nagaraja S, Tsoukias NM, Solodushko V, et al. Endothelial $\mathrm{Ca} 2+$ wavelets and the induction of myoendothelial feedback. Am J Physiol Cell Physiol. 2012;302(8):C1226-42.

36 Morgan AJ, Jacob R. Ca2+ influx does more than provide releasable $\mathrm{Ca} 2+$ to maintain repetitive spiking in human umbilical vein endothelial cells. Biochem J. 1996;320 (Pt 2): 505-17.

37 Neylon CB, Irvine RF. Synchronized repetitive spikes in cytoplasmic calcium in confluent monolayers of human umbilical vein endothelial cells. FEBS Lett. 1990;275(1-2): 173-6.
38 Pires PW, Sullivan MN, Pritchard HA, Robinson JJ, Earley S. Unitary TRPV3 channel $\mathrm{Ca} 2+$ influx events elicit endothelium-dependent dilation of cerebral parenchymal arterioles. Am J Physiol Heart Circ Physiol. 2015; 309(12):H2031-41

39 MacKay CE, Leo MD, Fernández-Peña C, Hasan R, Yin W, Mata-Daboin A, et al. Intravascular flow stimulates PKD2 (polycystin-2) channels in endothelial cells to reduce blood pressure. Elife. 2020;9:e60401.

40 Kevil CG, Okayama N, Trocha SD, Kalogeris TJ, Coe LL, Specian RD, et al. Expression of zonula occludens and adherens junctional proteins in human venous and arterial endothelial cells: role of occludin in endothelial solute barriers. Microcirculation. 1998;5(23): $197-210$

41 Lu Q, Zemskov EA, Sun X, Wang H, Yegambaram M, WuX, et al. Activation of the mechanosensitive $\mathrm{Ca} 2+$ channel TRPV4 induces endothelial barrier permeability via the disruption of mitochondrial bioenergetics. Redox Biol. 2020;38:101785.

42 Yin J, Hoffmann J, Kaestle SM, Neye N, Wang L, Baeurle J, et al. Negative-feedback loop attenuates hydrostatic lung edema via a cGMPdependent regulation of transient receptor potential vanilloid 4. Circ Res. 2008;102(8): 966-74. 